\title{
When should we attempt to make a silk purse from a sow's ear?
}

\author{
Eugene A. Grossi, MD
}

See related article on page 636 .

From the Department of Surgery, New York University Medical Center, New York, NY.

Received for publication Nov 17, 2003; accepted for publication Nov 19, 2003.

Address for reprints: Eugene A. Grossi, MD, Department of Surgery, New York University Medical Center, Suite 9V, Skirball Building, 530 First Ave, New York, NY 10028 (E-mail: grossi@cv.med.nyu. edu).

J Thorac Cardiovasc Surg 2004;127:618-9

$0022-5223 / \$ 30.00$

Copyright $\odot 2004$ by The American Association for Thoracic Surgery

doi:10.1016/j.jtcvs.2003.11.042

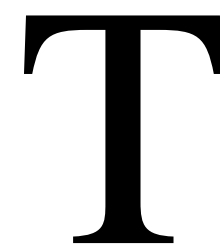

reatment of functional ischemic mitral regurgitation (MR) at the time of coronary revascularization remains a challenge. In spite of many recent contributions in this area, debate still rages over the optimal treatment of ischemic mitral insufficiency in the setting of infarcted myocardium. As the level of attention to this pathophysiologic process has increased significantly in the past few years, the quality of available data has risen substantially. In this issue of the Journal, Mallidi and colleagues ${ }^{1}$ offer interesting data that advance the discussion on this topic. The fundamental and as yet unanswered problem that surgeons are faced with is the following: When should we intervene on functional MR at the time of coronary artery bypass grafting (CABG), or, in other words, when should we attempt to make a silk purse out of a sow's ear?

Some important issues need to be reviewed before the question at hand can be profitably examined. Craig Miller, who has added considerably to this field, crystallized the nomenclature for ischemic MR, which had previously suffered from lack of uniformity. As he succinctly pointed out in an editorial in the Journal in 2001, "functional IMR. . .can be due to one of the following reasons: (1) simple annular dilatation (secondary to left ventricular [LV] enlargement), which causes incomplete mitral leaflet coaptation associated with Carpentier type I (normal) leaflet motion; (2) local LV remodeling with papillary muscle displacement producing apical tethering or tenting of the leaflets (with Carpentier type III-b restricted systolic leaflet motion); or (3) both mechanisms."

As surgeons, we are challenged by the knowledge that the presence of ischemic MR is associated with poorer outcomes in many different clinical scenarios. Patient survival after myocardial infarction and after percutaneous coronary intervention is reduced commensurate with the degree of ischemic MR. ${ }^{3,4}$ Similarly, Harris and associates $^{5}$ reported that intervention for ischemic mitral insufficiency at the time of CABG was especially beneficial to those patients with reduced ejection fractions. Such information might prompt some to adopt an aggressive policy of treating ischemic MR in the setting of left ventricular dysfunction. In contrast, Tolis and coworkers $^{6}$ and Duarte and associates ${ }^{7}$ have both reported series that show that revascularization alone can suffice in the presence of functional MR. However, it should be noted that the study by Duarte and associates ${ }^{7}$ focused on patients with preserved ventricular function. Perhaps such "good" patients might not obtain enough benefit from mitral repair to warrant the small additional risk of a concomitant valve procedure. Meanwhile, in the series by Tolis and coworkers, ${ }^{6} 90 \%$ of the patients had trace or mild MR. This study did not target the larger patient subset with moderate MR with which we are concerned.

In the current article Mallidi and colleagues ${ }^{1}$ carefully create matched cohorts of patients undergoing CABG with mild-to-moderate MR versus no MR. The analysis demonstrated equivalent late survival but decreased event-free survival and functional class in the MR group. The authors conclude that consideration should be given to repairing moderate MR in selected patients to improve long-term quality of life. Although this is new information, several small but important details must be examined as we consider its significance. One weakness is the lack of echocardiographic classification of MR, primarily because of the use of ventriculography alone for detection of MR. Only a small percentage of the patients had preoperative 
echocardiography, a more reliable and reproducible method for quantifying MR. ${ }^{8}$ This is an important limitation because it is the precise degree of MR that is being placed into the equation of analysis for the patient's long-term survival. In this era, echocardiography should be the standard for the diagnosis and evaluation of functional MR.

Additionally, the authors' conclusion that there was "progression of the MR" in their patients is difficult to substantiate because less than one third of the patients had any echocardiographic follow-up. In fact, this circumstance might have led to skewing of the follow-up dataset because those patients with more congestive heart failure might have been more likely to have been followed with echocardiography. Problematically, there is also a lack of granularity in Dr Mallidi's analysis of preoperative ventricular function and clinical status. Because more than half of the patients had ejection fractions of greater than $40 \%$, it is confusing why almost $89 \%$ of the patients without any MR were preoperatively categorized in New York Heart Association class 3 or 4 . From this dataset, it still remains unanswered whether those patients with reduced ventricular function had poorer outcomes. This is an especially important question because it is those patients who are the most important in this discussion. As Dr Gorman pointed out in his commentary on the Tolis article, ischemic MR can be thought of as the "ventricle crying out for help." 9

The article by Mallidi and colleagues ${ }^{1}$ adds to our knowledge as we attempt to deal with this difficult clinical choice. Our research efforts should remain focused on those patients with impaired ventricular function, the "sows' ears" who are at greatest risk for diminished late survival. It is in this patient subset that we might have the capability to improve outcomes. The question still remains open: In which patients and with what degree of ischemic MR will intervention provide improved survival, thereby justifying an added risk to the operative procedure?

\section{References}

1. Mallidi HR, Pelletier MP, Lamb J, Desai N, Sever J, Christakis GT, et al. Late outcomes in patients with uncorrected mild to moderate mitral regurgitation at the time of isolated coronary artery bypass grafting. J Thorac Cardiovasc Surg. 2004;127:636-44.

2. Miller DC. Ischemic mitral regurgitation redux - to repair or to replace? J Thorac Cardiovasc Surg. 2001;122:1059-62.

3. Grigioni F, Enriquez-Sarano M, Zehr KJ, Bailey KR, Tajik AJ. Ischemic mitral regurgitation: long-term outcome and prognostic implications with quantitative Doppler assessment. Circulation. 2001;103:1759-64.

4. Ellis SG, Whitlow PL, Raymond RE, Schneider JP. Impact of mitral regurgitation on long-term survival after percutaneous coronary intervention. Am J Cardiol. 2002;89:315-8.

5. Harris KM, Sundt TM 3rd, Aeppli D, Sharma R, Barzilai B. Can late survival of patients with moderate ischemic mitral regurgitation be impacted by intervention on the valve? Ann Thorac Surg. 2002;74: 1468-75.

6. Tolis GA Jr, Korkolis DP, Kopf GS, Elefteriades JA. Revascularization alone (without mitral valve repair) suffices in patients with advanced ischemic cardiomyopathy and mild-to-moderate mitral regurgitation. Ann Thorac Surg. 2002;74:1476-81.

7. Duarte IG, Shen Y, MacDonald MJ, Jones EL, Craver JM, Guyton RA. Treatment of moderate mitral regurgitation and coronary disease by coronary bypass alone: late results. Ann Thorac Surg. 1999;68:426-30.

8. Castello R, Lenzen P, Aguirre F, Labovitz AJ. Quantitation of mitral regurgitation by transesophageal echocardiography with Doppler color flow mapping: correlation with cardiac catheterization. J Am Coll Cardiol. 1992;19:1516-21.

9. Gorman RC, Gorman JH. Does repair of ischemic mitral regurgitation help? Ann Thorac Surg. 2003;76:1775-6.

\section{The Journal of Thoracic and Cardiovascular Surgery Conflict of Interest Policy}

To assure fairness to authors submitting work for consideration in The Journal of Thoracic and Cardiovascular Surgery, a mechanism exists for managing conflicts of interest. The editor and each of the section editors complete a "Conflict of Interest" form that identifies any and all relationships with commercial and other academic entities. When the editor has a potential conflict because of a relationship with another entity or author, the editor appoints an alternate editor from among the section editors or editorial board members who assumes the entire responsibility for final decisions on the manuscript in question. The editor does not read the reviews that are submitted nor engage in discussing the manuscript prior to the final decision. When the conflict of interest involves a section editor, a "guest section editor" is appointed who fills the role normally played by the conflicted section editor. All members of the editorial board and reviewers are asked to indicate any conflict of interest when they agree to review a manuscript. 